\title{
Tamoxifen reduces hepatic VLDL production and GH secretion in women: a possible mechanism for steatosis development
}

\author{
Vita Birzniece ${ }^{1,2,3}$, P Hugh R Barrett ${ }^{4}$ and Ken K Y Ho ${ }^{1,5}$ \\ ${ }^{1}$ Garvan Institute of Medical Research, Sydney, New South Wales, Australia, ${ }^{2}$ School of Medicine, Western Sydney \\ University, Penrith, New South Wales, Australia, ${ }^{3}$ School of Medicine, University of New South Wales, Sydney, \\ New South Wales, Australia, ${ }^{4}$ School of Biomedical Sciences, Faculty of Health and Medical Sciences, and Faculty of \\ Engineering and Mathematical Sciences, The University of Western Australia, Perth, Western Australia, Australia, and \\ ${ }^{5}$ Centres of Health Research, Princess Alexandra Hospital, Brisbane, Queensland, Australia
}

Correspondence should be addressed to V Birzniece Email v.birzniece@westernsydney. edu.au

\begin{abstract}
Context: Growth hormone (GH) stimulates hepatic synthesis of very-low-density lipoproteins (VLDL), whereas hepatic steatosis develops as a result of GH deficiency. Steatosis is also a complication of tamoxifen treatment, the cause of which is not known. As tamoxifen inhibits the secretion and action of $\mathrm{GH}$, we hypothesize that it induces steatosis by inhibiting hepatic VLDL export.

Aim: To investigate whether tamoxifen reduces hepatic VLDL secretion.

Design: Eight healthy, normolipidemic women (age: $64.4 \pm 2.1$ years) were studied in random sequence at baseline, after 2 weeks of tamoxifen ( $20 \mathrm{mg} /$ day) and after 2 weeks of estradiol valerate (EV; $2 \mathrm{mg} /$ day) treatments, separated by a 4-week washout period. The kinetics of apolipoprotein $B(a p o B)$, the structural protein of VLDL particles, were measured using a stable isotope $2 \mathrm{H}^{3}$-leucine turnover technique. VLDL-apoB fractional catabolic rate (FCR) was determined using a multicompartment model. VLDL-apoB secretion was estimated as the product of FCR and VLDLapoB concentration. GH response to arginine stimulation, circulating levels of IGF-1, FFA, and TG, along with TG content in VLDL were measured.

Results: Tamoxifen significantly $(P<0.05)$ reduced VLDL-apoB concentration and secretion by $27.3 \pm 7.8 \%$ and $29.8 \pm 10.2 \%$, respectively. In contrast, EV did not significantly change VLDL-apoB concentration or secretion. Tamoxifen but not $\mathrm{EV}$ significantly reduced $(P<0.05) \mathrm{GH}$ response to arginine stimulation. Both treatments significantly lowered $(P<0.05)$ circulating IGF-1.

Conclusion: Inhibition of VLDL secretion may contribute to the development of fatty liver during tamoxifen therapy. As GH stimulates VLDL secretion, the development of steatosis may arise secondarily from GH insufficiency induced by tamoxifen.
\end{abstract}

\section{Introduction}

Hepatic steatosis develops in up to $50 \%$ of patients with breast cancer treated with tamoxifen $(1,2,3,4)$. However, the mechanism by which tamoxifen induces fatty liver is unknown.

Steatosis is a common complication of growth hormone deficiency (GHD). Fatty liver, assessed by fatty
() 2017 European Society of Endocrinology Printed in Great Britain infiltration on imaging studies or liver biopsy based on standardized grading system, is found in up to three quarters of GHD adults in Japan $(5,6)$. Up to $30 \%$ of patients with GHD develop steatosis and GH therapy reverses this based on histological evaluation and normalization of liver enzymes $(6,7,8)$. Hepatic steatosis develops within

Published by Bioscientifica Ltd. 
3 years of the diagnosis of hypothalamic or pituitary dysfunction, especially with obesity (9). Furthermore, in patients with non-alcoholic fatty liver disease (NAFLD), low GH levels are associated with a more advanced stage of NAFLD (10). Evidence supporting a pathophysiologic role of GH comes from the observation that a loss of GH receptor function in the liver leads to steatosis (11). Liverspecific deletion of the GH receptor causes abnormal intrahepatic lipid metabolism, which is not corrected by IGF-1 administration (12). GH stimulates fat oxidation and the synthesis of very-low-density lipoproteins (VLDL) for hepatic export of triglycerides (TGs) $(13,14)$. Thus, GH plays a vital role in regulating hepatic lipid metabolism.

Our research on the GH system has provided strong evidence that estrogens regulate the secretion and the action of GH $(15,16,17)$. SERM are synthetic estrogens, compounds that possess tissue-specific antagonist and agonist properties. In the case of tamoxifen, it acts centrally as an estrogen receptor antagonist and peripherally on the liver as an agonist $(18,19)$. Because estrogens drive GH secretion centrally, tamoxifen markedly reduces GH secretion (17). Estrogens inhibit hepatic GHR signaling and when taken by the oral route antagonizes the metabolic actions of GH on the liver, resulting in a fall in IGF-1 and fatty acid oxidation $(20,21,22,23,24)$. The fall in circulating IGF-1 by oral estrogens can trigger a secondary increase in GH secretion from loss of central feedback inhibition. Tamoxifen exerts hepatic effects similar to those of estrogens. However, unlike estrogens, tamoxifen does not cause a secondary increase in GH because its central action as an antagonist prevents the increase in GH secretion (17). Thus, while both inhibit the hepatic actions of $\mathrm{GH}$, tamoxifen evokes a more severe GH-deficient state from additional inhibition of GH secretion.

These findings suggest that steatosis developing from tamoxifen may arise secondarily from a GH-deficient state caused by its suppression of the system. Unlike with tamoxifen, steatosis is not a recognized complication of oral estrogen use, suggesting that the underlying mechanism is unlikely to arise from an estrogen agonist effect on the liver. Because estrogen and tamoxifen exert contrasting central effects, it is conceivable that steatosis may develop from impaired VLDL production as a result of reduced GH secretion during tamoxifen treatment.

The aim of this study was to investigate whether hepatic VLDL production is inhibited by tamoxifen. We have compared VLDL dynamics during tamoxifen and estradiol valerate treatment in postmenopausal women using stable isotope methodology.

\section{Methods}

\section{Subjects}

Eight healthy women (mean age: $64.4 \pm 2.1$ years; mean BMI: $23.7 \pm 1.2 \mathrm{~kg} / \mathrm{m}^{2}$ ) were recruited from the community through advertisements. Study participants were normolipidemic, in good general health and had normal hematological tests, renal and hepatic function. Exclusion criteria included BMI $\geq 30 \mathrm{~kg} / \mathrm{m}^{2}$, hypothalamic or pituitary disorders, diabetes mellitus, cancer and chronic renal or hepatic illnesses, or taking any medications known to interfere with endocrine systems. Study participants were instructed to follow their usual diet and physical activity throughout the study. St Vincent's Hospital Human Research Ethics Committee approved the study, which was conducted in accordance with the principles of the Declaration of Helsinki. The study was registered with the Australian New Zealand Clinical Trials Registry (ACTRN12611001093976).

\section{Study design}

This was an open label study of tamoxifen (Genox) and estradiol valerate administration. The dose of tamoxifen was $20 \mathrm{mg}$ /day and for estradiol valerate (EV) $2 \mathrm{mg} /$ day. Study medications were administered in randomized order for two weeks each, with a 4-week washout in between. Study participants were studied in the Clinical Research Facility, Garvan Institute of Medical Research after an overnight fast. On each visit, including baseline (no intervention), assessment of VLDL turnover was performed, GH response to arginine stimulation, and serum IGF-1, free fatty acids (FFA), TG levels were measured. Study bloods were collected, and serum samples were obtained by centrifugation and stored at $-80^{\circ} \mathrm{C}$ until analysis.

\section{VLDL turnover}

We quantified hepatic VLDL secretion by stable isotope $2 \mathrm{H}^{3}$-leucine turnover technique (25). It is assumed that plasma alpha-KIC is in equilibrium with intrahepatic leucine and reflects the enrichment of hepatic leucine transfer ribonucleic acid, which is necessary for the production of apoB, the principal structural apolipoprotein of VLDL. The steady-state isotope enrichment of the precursor pool occurs within $30-45 \mathrm{~min}$ of $2 \mathrm{H}^{3}$-leucine infusion and remains constant throughout the study. 
After an overnight fast, blood samples were taken before and during the 3 -h primed $(1.34 \mathrm{mg} / \mathrm{kg})$ constant infusion of $2 \mathrm{H}^{3}$-leucine at a rate of $1.34 \mathrm{mg} / \mathrm{kg} / \mathrm{h}$. EDTA blood samples were centrifuged immediately, and plasma was stored at $4^{\circ} \mathrm{C}$ for up to $8 \mathrm{~h}$. The VLDL fraction was then isolated from plasma through ultracentrifugation $\left(50000 \mathrm{rpm}\right.$ at $20^{\circ} \mathrm{C}$ for $16 \mathrm{~h}$ ) and recovered by aspiration.

Laboratory methods for measurement of VLDLapoB turnover have been described previously by Chan and co-authors (26). We quantified the concentration of VLDL-apoB by the Lowry method. ApoB was precipitated with $50 \%$ isopropanol and delipidated by $100 \%$ isopropanol, made soluble in alkaline deoxycholate solution and protein estimated by the Lowry method. Isotopic enrichment of VLDL and plasma was measured by gas chromatography-mass spectrometry (GC-MS) as previously described (26).

VLDL-apoB fractional catabolic rate (FCR) is that fraction of the VLDL-apoB pool irreversibly cleared from the plasma per day. VLDL-apoB secretion rate was estimated as the product of FCR and VLDL-apoB concentration. Pool size is the mass of tracee in the VLDL pool determined as the product of plasma volume and trace concentration.

The multicompartment model included a compartment 1 , which reflected the plasma tracer/tracee ratio of the leucine tracer in plasma. Compartment 2 represents intrahepatic delay that accounts for the time required for the synthesis and secretion of VLDL-apoB into plasma. Compartment 3 represents the plasma VLDL-apoB. The rate constant out of compartment 3 is equivalent to the VLDL-apoB FCR. The SAAM II software (The Epsilon Group, Charlottesville, VA, USA) was used to fit the model to the tracer data.

\section{Arginine stimulation test}

Subjects rested on a bed for at least $30 \mathrm{~min}$ before the baseline blood samples were taken. Thirty grams of L-Arginine hydrochloride (Phebra Pty Ltd, Australia) was infused over 30-min period. Blood samples for GH level measurements were taken at 0 and 30, 60 and 90 min after commencement of arginine infusion.

\section{Analytical methods}

All samples for any individual were measured in the same assay run for each analyte. Serum GH was measured by Immulite 2000 (L2KGRH, WHO NIBSC 2nd IS 98/574;
Siemens Medical Solution Diagnostics, Los Angeles, CA, USA). The inter-assay and intra-assay $\mathrm{CV}$ s for $\mathrm{GH}$ at $3 \mathrm{ng} / \mathrm{mL}$ were $5.8 \%$ and $5.7 \%$, respectively. Serum IGF-1 was measured by RIA after acid ethanol extraction as previously described (17). The CVs for IGF- 1 were $8.3 \%$ at $14.7 \mathrm{nmol} / \mathrm{L}$ and $7.4 \%$ at $28.6 \mathrm{nmol} / \mathrm{L}$. TG was measured using Enzyme Colorimetric method by Cobas 701 autoanalyzer (Roche Diagnostics). The inter-assay CV for TG was $2.6 \%$ at $2.9 \mathrm{mmol} / \mathrm{L} .17 \beta$-Estradiol was measured by electrochemiluminescence immunoassay with inter-assay $\mathrm{CV}$ of $4.7 \%$ at $166 \mathrm{pmol} / \mathrm{L}$.

\section{Statistical analysis}

Treatment effects were assessed by factorial ANOVA followed by paired $t$-tests with Bonferroni's correction where appropriate. The GH response to arginine data was logarithmically transformed and analyzed by repeated measures ANOVA. Results were expressed as mean with standard errors (s.E.M.), and a $P$ value of less than 0.05 was considered to be significant. Statistical analysis was undertaken using the statistical software package SPSS (IBM SPSS Statistics 21).

\section{Results}

\section{VLDL metabolism}

Tamoxifen, but not EV, significantly $(P<0.05)$ lowered mean VLDL-apoB concentration $(\Delta-27.3 \pm 7.8 \%$; Fig. 1 and Table 1). The change in VLDL-apoB concentration between tamoxifen and EV treatments was significantly different $(P<0.05)$. Tamoxifen significantly lowered VLDL-apoB secretion rate by $29.8 \pm 10.2 \%(P<0.05)$, while EV treatment did not significantly affect this. Neither tamoxifen nor EV significantly changes the FCR of VLDL-apoB.

Both tamoxifen and EV did not significantly change plasma or VLDL triglyceride concentrations. The VLDL-TG to VLDL-apoB ratio, a measure of the TG content of VLDL particles, also did not change significantly with tamoxifen or EV treatments (Table 1).

\section{Effects on GH and IGF-1}

Tamoxifen significantly reduced the peak GH response to arginine stimulation by $45.3 \pm 8.9 \%(P<0.01$; Table 1$)$. $\mathrm{EV}$ did not significantly affect the peak GH response to stimulation (Fig. 2). Compared with baseline, 
A

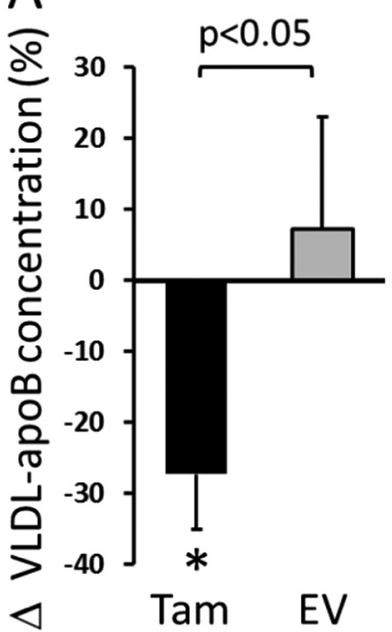

B

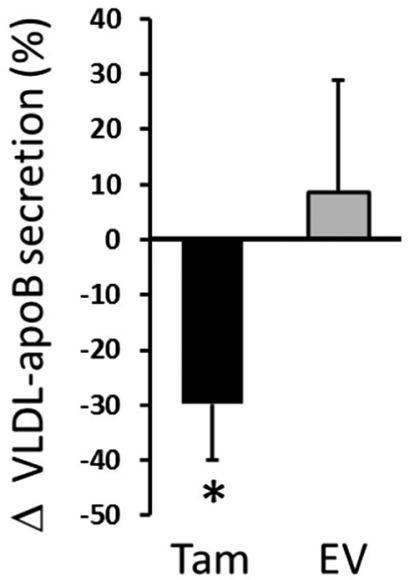

Figure 1

Changes in VLDL-apoB concentration ( $A$ ) and VLDL-apoB secretion (B) during tamoxifen (Tam; $20 \mathrm{mg} /$ day) and estradiol valerate (EV; $2 \mathrm{mg} /$ day) treatments. ${ }^{*} P<0.05$ compared to baseline. Data are expressed as means \pm S.E.M.

administration of tamoxifen or EV significantly reduced circulating IGF-1 concentrations $(\Delta-14.8 \pm 5.3 \%$ and $-21.4 \pm 4.7 \%$, respectively; $P<0.05$; Table 1). IGF-1 levels following tamoxifen and EV treatments were not significantly different.

\section{Other measurements}

FFA concentrations did not change significantly with either treatments. Mean circulating estradiol levels increased significantly during treatment with EV $(P<0.01$; Table 1$)$.

\section{Discussion}

We investigated the effects of tamoxifen and estradiol valerate on hepatic VLDL metabolism and on the $\mathrm{GH}$ system in healthy postmenopausal women using isotopic tagging of apoB, the principal structural protein of VLDL. VLDL-apoB concentration was significantly lower during tamoxifen than during EV treatment. Tamoxifen but not EV significantly reduced hepatic VLDL secretion, while both treatments did not affect the FCR. Neither tamoxifen nor EV significantly modified the TG content of VLDL. Tamoxifen but not EV treatment significantly reduced the peak GH response to stimulation. Both tamoxifen and EV significantly reduced IGF-1 levels to a similar extent. In summary, tamoxifen but not EV reduced hepatic VLDL production and reduced GH secretion.

VLDL is composed of a core of triglycerides, surrounded by cholesterol, cholesteryl esters, phospholipids and apolipoproteins, of which apoB is the principal apolipoprotein. VLDL secretion rate depends on availability of intrahepatic lipid substrate. Fatty acids taken up by the liver are either oxidized or reesterified to triglycerides and exported from the liver as VLDL particles. Therefore, a block in either beta-oxidation or VLDL export leads to TG accumulation and the development of a fatty liver.

GH plays a pivotal role in hepatic lipid metabolism. Rodent studies reveal that loss of hepatic GH receptor function leads to TG accumulation in the liver (11). Several clinical studies have described the occurrence of steatosis in patients with GH deficiency, which resolves with $\mathrm{GH}$ therapy $(7,8)$. Because $\mathrm{GH}$ stimulates hepatic fatty acid oxidation (13) and VLDL secretion $(14,27)$, it is likely that steatosis develops in GHD

Table 1 Endpoint measures at baseline and during the treatment with tamoxifen $(20 \mathrm{mg} /$ day) and estradiol valerate ( $2 \mathrm{mg} / \mathrm{day})$.

Data are expressed as means \pm S.E.M.

\begin{tabular}{l} 
Outcome measures \\
\hline Weight $(\mathrm{kg})$ \\
Estradiol $(\mathrm{pmol} / \mathrm{L})$ \\
GH max $(\mathrm{ng} / \mathrm{mL})$ \\
IGF-1 (nmol/L) \\
VLDL-apoB concentration (mg/L) \\
VLDL-apoB FCR (pools/days) \\
VLDL-apoB secretion (mg/kg/day) \\
TG (mmol/L) \\
VLDL-TG (mmol/L) \\
VLDL-TG to VLDL-apoB ratio \\
FFA ( $\mu \mathrm{mol} / \mathrm{L})$
\end{tabular}

\begin{tabular}{r}
\hline Baseline \\
\hline $64.0 \pm 3.0$ \\
$11.7 \pm 4.1$ \\
$17.3 \pm 4.0$ \\
$14.9 \pm 1.0$ \\
$31.1 \pm 5.6$ \\
$3.8 \pm 0.7$ \\
$4.5 \pm 1.1$ \\
$0.84 \pm 0.1$ \\
$1.06 \pm 0.1$ \\
$4.5 \pm 0.9$ \\
$574.5 \pm 66$
\end{tabular}

\begin{tabular}{c}
\hline Tamoxifen \\
\hline $63.8 \pm 3.1$ \\
$10.5 \pm 3.7$ \\
$10.4 \pm 3.5^{* *}$ \\
$12.7 \pm 1.2^{*}$ \\
$21.8 \pm 4.8^{*}$ \\
$3.2 \pm 0.8$ \\
$3.0 \pm 0.8^{*}$ \\
$0.81 \pm 0.1$ \\
$1.03 \pm 0.2$ \\
$6.2 \pm 1.3$ \\
$574.2 \pm 76$
\end{tabular}

\begin{tabular}{c}
\hline Estradiol \\
\hline $64.3 \pm 3.1$ \\
$349.5 \pm 71 * * \wedge$ \\
$20.5 \pm 10.8$ \\
$11.7 \pm 1.0^{* *}$ \\
$29.0 \pm 4.5^{\wedge}$ \\
$3.5 \pm 0.5$ \\
$4.0 \pm 0.6$ \\
$1.0 \pm 0.1$ \\
$1.29 \pm 0.2$ \\
$4.9 \pm 0.9$ \\
$601.1 \pm 102$
\end{tabular}

${ }^{*} P<0.05$ compared with baseline; ${ }^{*} * P<0.01$ compared with baseline; ${ }^{\wedge} P<0.05$ compared with tamoxifen. FCR, fractional catabolic rate; FFA, free fatty acids; GH max, peak GH response to arginine stimulation, conversion factor: $1 \mathrm{IU} / \mathrm{L}=0.33 \mu \mathrm{g} / \mathrm{L}$; TG, triglycerides; VLDL, very-low-density lipoprotein. 


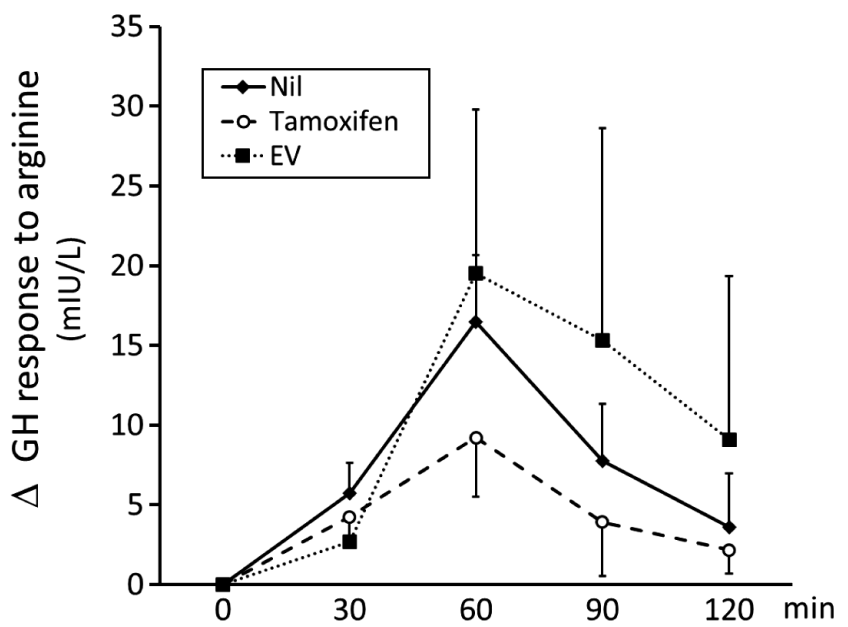

Figure 2

Change from pre-stimulation serum GH levels at 30, 60, 90 and $120 \mathrm{~min}$ after arginine infusion measured before (nil; solid line), during oral treatment with estradiol valerate (EV; $2 \mathrm{mg} /$ day; dotted line) and during tamoxifen treatment (20 mg/day; dashed line). Data are expressed as means \pm s.E.M. Conversion factor: $1 \mathrm{IU} / \mathrm{L}=0.33 \mu \mathrm{g} / \mathrm{L}$.

patients from suppression of fatty acid oxidation and of VLDL production.

Our previous work has provided strong evidence that tamoxifen exerts a more profound suppressive effect on the GH system than classical estrogen such as EV. While both tamoxifen and EV antagonize the action of GH on the liver, tamoxifen exerts an additional central effect of inhibiting GH secretion as observed in the GH response to arginine, confirming our earlier report (17). We investigated whether the double blow effect which creates a more profound GH-deficient state reduced VLDL production. Our findings provide evidence that steatosis develops during tamoxifen most likely from impaired VLDL export arising from the induction of a profound GH-deficient state.

Studies have demonstrated that estrogens may stimulate VLDL production depending on the route of administration. Oral but not transdermal estrogen enhances the fractional secretion and production rate of VLDL in particular the light fraction of VLDL particles $(28,29)$. As oral but not parenteral route of estrogen delivery stimulates GH secretion $(17,20)$, the increase in GH output may in turn stimulate hepatic VLDL production. We did not observe a significant increase in GH secretion or VLDL production during EV administration although there was a small trend. Steatosis is not a recognized complication of oral estrogen use. The finding that VLDL secretion is either unaffected or may be stimulated by oral estrogens supports the hypothesis that suppression of GH-stimulated VLDL export is a plausible mechanism for the development of steatosis.

It is not clear from clinical studies whether GH or IGF-1 regulates hepatic VLDL metabolism. However, rodent studies provide little evidence that IGF-1 has a major role in regulating VLDL metabolism in the liver. In vitro studies report no direct effect of IGF-1 on VLDL secretion in isolated rat hepatocytes, contrary to that of GH $(27,30)$. Steatosis that develops as a consequence of liver-specific deletion of the GH receptor is not improved by IGF-1 treatment (12). Steatosis does not develop in liver-specific IGF-1-deficient mice (31). Thus, the collective evidence points to a direct non-IGF-1 mediated action of GH on VLDL secretion.

The intracellular biochemical mechanisms by which VLDL secretion is reduced by tamoxifen is not known. The assembly and secretion of apoB-containing lipoproteins are strictly dependent on the microsomal triglyceride transfer protein (MTP), which shuttles triglycerides into the nascent VLDL particle $(32,33)$. Animal studies show that continuous GH infusion stimulates hepatic MTP mRNA and protein levels (34). Thus, tamoxifen, by inhibiting GH secretion, could reduce MTP synthesis in the liver, reducing VLDL formation.

A direct effect of tamoxifen, independent of $\mathrm{GH}$, on hepatocytes cannot be ruled out. It is been proposed from in vitro experiments that tamoxifen induces hepatic steatosis by impairing beta-oxidation and respiration, or by increasing fatty acid synthesis through upregulation of SREBP-1c pathway $(35,36)$. Other studies report no direct effect of tamoxifen on hepatocyte fatty acid oxidation, whereas systemic treatment of tamoxifen in mice substantially increases hepatic triglyceride content and activates fatty acid synthesis (37). In vitro incubation of VLDL with tamoxifen resulted in increased TG content in VLDL particles (38); however, studies investigating the direct effect of tamoxifen on hepatic VLDL production are scarce. Studies comparing the in vitro effects of tamoxifen and estradiol have not been reported. Thus, the possibility that tamoxifen direct regulates VLDL turnover and assembly cannot be excluded.

This study has some limitations, including a relatively small sample size, although each patient completed each treatment and as such served as their own control. In addition, the duration of the tracer study was relatively short, limiting the identification of kinetic heterogeneity within the VLDL-apoB fraction. Longer term studies may provide more precise measures of VLDL-apoB kinetics. 
However, as the primary determinant of VLDL-apoB concentration is secretion rate it is unlikely that small errors in FCR impact on our findings.

In summary, tamoxifen significantly reduced hepatic VLDL secretion in healthy postmenopausal women. Tamoxifen inhibited GH secretion, inducing a GH-deficient state. As $\mathrm{GH}$ is a potent stimulant of hepatic lipid metabolism and VLDL secretion, we propose that the reduction in VLDL secretion may arise in part from profound suppression of the GH-IGF-1 axis. Diminished hepatic VLDL secretion may contribute to the development of fatty liver during tamoxifen therapy.

\section{Declaration of interest}

The authors declare that there is no conflict of interest that could be perceived as prejudicing the impartiality of the research reported.

\section{Funding}

This work was supported by the National Health and Medical Research Council of Australia (grant number GNT1064365). The study was registered with the Australian New Zealand Clinical Trials Registry (ACTRN12611001093976)

\section{Acknowledgements}

PHRB is a Senior Research Fellow of the NHMRC. We thank Alphapharm for providing Genox, research nurse for clinical assistance, Surya Sutanto, and the Endocrinology Laboratory, Royal Prince Alfred Hospital, Sydney, Australia.

\section{References}

1 Ogawa Y, Murata Y, Nishioka A, Inomata T \& Yoshida S. Tamoxifeninduced fatty liver in patients with breast cancer. Lancet $1998 \mathbf{3 5 1}$ 725. (doi:10.1016/S0140-6736(05)78493-2)

2 Murata Y, Ogawa Y, Saibara T, Nishioka A, Fujiwara Y, Fukumoto M, Inomata T, Enzan H, Onishi S \& Yoshida S. Unrecognized hepatic steatosis and non-alcoholic steatohepatitis in adjuvant tamoxifen for breast cancer patients. Oncology Reports 20007 1299-1304.

3 Nishino M, Hayakawa K, Nakamura Y, Morimoto T \& Mukaihara S. Effects of tamoxifen on hepatic fat content and the development of hepatic steatosis in patients with breast cancer: high frequency of involvement and rapid reversal after completion of tamoxifen therapy. American Journal of Roentgenology 2003180 129-134. (doi:10.2214/ajr.180.1.1800129)

4 Liu CL, Huang JK, Cheng SP, Chang YC, Lee JJ \& Liu TP. Fatty liver and transaminase changes with adjuvant tamoxifen therapy. Anticancer Drugs 200617 709-713. (doi:10.1097/01. cad.0000215056.47695.92)

5 Ichikawa T, Hamasaki K, Ishikawa H, Ejima E, Eguchi K \& Nakao K. Non-alcoholic steatohepatitis and hepatic steatosis in patients with adult onset growth hormone deficiency. Gut 200352914. (doi:10.1136/gut.52.6.914)

6 Nishizawa H, Iguchi G, Murawaki A, Fukuoka H, Hayashi Y, Kaji H, Yamamoto M, Suda K, Takahashi M, Seo Y et al. Nonalcoholic fatty liver disease in adult hypopituitary patients with GH deficiency and the impact of GH replacement therapy. European Journal of Endocrinology 2012167 67-174. (doi:10.1530/EJE-12-0252)
7 Takahashi Y, Iida K, Takahashi K, Yoshioka S, Fukuoka H, Takeno R, Imanaka M, Nishizawa H, Takahashi M, Seo Y et al. Growth hormone reverses nonalcoholic steatohepatitis in a patient with adult growth hormone deficiency. Gastroenterology 2007132 938-943. (doi:10.1053/j.gastro.2006.12.024)

8 Fukuda I, Hizuka N, Yasumoto K, Morita J, Kurimoto M \& Takano K. Metabolic co-morbidities revealed in patients with childhood-onset adult GH deficiency after cessation of GH replacement therapy for short stature. Endocrine Journal 200855 977-984. (doi:10.1507/ endocrj.K08E-079)

9 Adams LA, Feldstein A, Lindor KD \& Angulo P. Nonalcoholic fatty liver disease among patients with hypothalamic and pituitary dysfunction. Hepatology 200439 909-914. (doi:10.1002/hep.20140)

10 Ichikawa T, Nakao K, Hamasaki K, Furukawa R, Tsuruta S, Ueda Y, Taura N, Shibata H, Fujimoto M, Toriyama K et al. Role of growth hormone, insulin-like growth factor 1 and insulin-like growth factorbinding protein 3 in development of non-alcoholic fatty liver disease. Hepatology International 20071 287-294. (doi:10.1007/s12072-0079007-4)

11 Barclay JL, Nelson CN, Ishikawa M, Murray LA, Kerr LM, McPhee TR, Powell EE \& Waters MJ. GH-dependent STAT5 signaling plays an important role in hepatic lipid metabolism. Endocrinology 2011152 181-192. (doi:10.1210/en.2010-0537)

12 Fan Y, Menon RK, Cohen P, Hwang D, Clemens T, DiGirolamo DJ, Kopchick JJ, Le Roith D, Trucco M \& Sperling MA. Liver-specific deletion of the growth hormone receptor reveals essential role of growth hormone signaling in hepatic lipid metabolism. Journal of Biological Chemistry 2009284 19937-19944. (doi:10.1074/jbc. M109.014308)

13 Zhao JT, Cowley MJ, Lee P, Birzniece V, Kaplan W \& Ho KK. Identification of novel GH-regulated pathway of lipid metabolism in adipose tissue: a gene expression study in hypopituitary men. Journal of Clinical Endocrinology and Metabolism 201196 E1188-E1196. (doi:10.1210/jc.2010-2679)

14 Christ ER, Cummings MH, Albany E, Umpleby AM, Lumb PJ, Wierzbicki AS, Naoumova RP, Boroujerdi MA, Sonksen PH \& RussellJones DL. Effects of growth hormone $(\mathrm{GH})$ replacement therapy on very low density lipoprotein apolipoprotein B100 kinetics in patients with adult GH deficiency: a stable isotope study. Journal of Clinical Endocrinology and Metabolism 199984 307-316. (doi:10.1210/ jc.84.1.307)

15 O'Sullivan AJ, Crampton LJ, Freund J \& Ho KK. The route of estrogen replacement therapy confers divergent effects on substrate oxidation and body composition in postmenopausal women. Journal of Clinical Investigation 1998102 1035-1040. (doi:10.1172/jci2773)

16 Birzniece V, Meinhardt U, Gibney J, Johannsson G, Baxter RC, Seibel MJ \& Ho KK. Modulatory effect of raloxifene and estrogen on the metabolic action of growth hormone in hypopituitary women. Journal of Clinical Endocrinology and Metabolism 201095 2099-2106. (doi:10.1210/jc.2009-2743)

17 Birzniece V, Sata A, Sutanto S \& Ho KK. Paracrine regulation of growth hormone secretion by estrogen in women. Journal of Clinical Endocrinology and Metabolism 201095 3771-3776. (doi:10.1210/ jc.2010-0476)

18 Lofgren L, Wallberg B, Wilking N, Fornander T, Rutqvist LE, Carlstrom K, von Schoultz B \& von Schoultz E. Tamoxifen and megestrol acetate for postmenopausal breast cancer: diverging effects on liver proteins, androgens, and glucocorticoids. Medical Oncology 200421 309-318. (doi:10.1385/MO:21:4:309)

19 Riggs BL \& Hartmann LC. Selective estrogen-receptor modulators mechanisms of action and application to clinical practice. New England Journal of Medicine 2003348 618-629. (doi:10.1056/ NEJMra022219)

20 Weissberger AJ, Ho KK \& Lazarus L. Contrasting effects of oral and transdermal routes of estrogen replacement therapy on 24-hour growth hormone $(\mathrm{GH})$ secretion, insulin-like growth factor I, and 
GH-binding protein in postmenopausal women. Journal of Clinical Endocrinology and Metabolism 199172 374-381. (doi:10.1210/jcem72-2-374)

21 Gibney J, Johannsson G, Leung KC \& Ho KK. Comparison of the metabolic effects of raloxifene and oral estrogen in postmenopausal and growth hormone-deficient women. Journal of Clinical Endocrinology and Metabolism 200590 3897-3903. (doi:10.1210/ jc.2005-0173)

22 Bellantoni MF, Vittone J, Campfield AT, Bass KM, Harman SM \& Blackman MR. Effects of oral versus transdermal estrogen on the growth hormone/insulin-like growth factor I axis in younger and older postmenopausal women: a clinical research center study. Journal of Clinical Endocrinology and Metabolism 199681 2848-2853. (doi:10.1210/jcem.81.8.8768841)

23 Sonnet E, Lacut K, Roudaut N, Mottier D, Kerlan V \& Oger E. Effects of the route of oestrogen administration on IGF-1 and IGFBP-3 in healthy postmenopausal women: results from a randomized placebo-controlled study. Clinical Endocrinology 200766 626-631. (doi:10.1111/j.1365-2265.2007.02783.x)

24 Leung KC, Doyle N, Ballesteros M, Sjogren K, Watts CK, Low TH, Leong GM, Ross RJ \& Ho KK. Estrogen inhibits GH signaling by suppressing GH-induced JAK2 phosphorylation, an effect mediated by SOCS-2. PNAS 2003100 1016-1021. (doi:10.1073/pnas.0337600100)

25 Chan DC, Barrett PH \& Watts GF. Lipoprotein transport in the metabolic syndrome: methodological aspects of stable isotope kinetic studies. Clinical Science 2004107 221-232. (doi:10.1042/CS20040108)

26 Chan DC, Gan SK, Wong AT, Barrett PH \& Watts GF. Association between skeletal muscle fat content and very-low-density lipoproteinapolipoprotein B-100 transport in obesity: effect of weight loss. Diabetes, Obesity and Metabolism 201416 994-1000. (doi:10.1111/ dom.12311)

27 Linden D, Sjoberg A, Asp L, Carlsson L \& Oscarsson J. Direct effects of growth hormone on production and secretion of apolipoprotein $\mathrm{B}$ from rat hepatocytes. American Journal of Physiology: Endocrinology and Metabolism 2000279 E1335-E1346.

28 Walsh BW, Schiff I, Rosner B, Greenberg L, Ravnikar V \& Sacks FM. Effects of postmenopausal estrogen replacement on the concentrations and metabolism of plasma lipoproteins. New England Journal of Medicine 1991325 1196-1204. (doi:10.1056/ NEJM199110243251702)
29 Campos H, Walsh BW, Judge H \& Sacks FM. Effect of estrogen on very low density lipoprotein and low density lipoprotein subclass metabolism in postmenopausal women. Journal of Clinical Endocrinology and Metabolism 199782 3955-3963. (doi:10.1210/ jcem.82.12.4437)

30 Sjoberg A, Oscarsson J, Olofsson SO \& Eden S. Insulin-like growth factor-I and growth hormone have different effects on serum lipoproteins and secretion of lipoproteins from cultured rat hepatocytes. Endocrinology 1994135 1415-1421. (doi:10.1210/ endo.135.4.7925103)

31 Yakar S, Setser J, Zhao H, Stannard B, Haluzik M, Glatt V, Bouxsein ML, Kopchick JJ \& LeRoith D. Inhibition of growth hormone action improves insulin sensitivity in liver IGF-1-deficient mice. Journal of Clinical Investigation 2004113 96-105. (doi:10.1172/ JCI200417763)

32 Olofsson SO, Asp L \& Boren J. The assembly and secretion of apolipoprotein B-containing lipoproteins. Current Opinion in Lipidology 199910 341-346. (doi:10.1097/00041433-199908000-00008)

33 Shelness GS \& Ledford AS. Evolution and mechanism of apolipoprotein B-containing lipoprotein assembly. Current Opinion in Lipidology 2005 16 325-332. (doi:10.1097/01.mol.0000169353.12772.eb)

34 Ameen C \& Oscarsson J. Sex difference in hepatic microsomal triglyceride transfer protein expression is determined by the growth hormone secretory pattern in the rat. Endocrinology 2003144 3914-3921. (doi:10.1210/en.2003-0518)

35 Zhao F, Xie P, Jiang J, Zhang L, An W \& Zhan Y. The effect and mechanism of tamoxifen-induced hepatocyte steatosis in vitro. International Journal of Molecular Sciences 201415 4019-4030. (doi:10.3390/ijms15034019)

36 Larosche I, Letteron P, Fromenty B, Vadrot N, Abbey-Toby A, Feldmann G, Pessayre D \& Mansouri A. Tamoxifen inhibits topoisomerases, depletes mitochondrial DNA, and triggers steatosis in mouse liver. Journal of Pharmacology and Experimental Therapeutics 2007321 526-535. (doi:10.1124/jpet.106.114546)

37 Cole LK, Jacobs RL \& Vance DE. Tamoxifen induces triacylglycerol accumulation in the mouse liver by activation of fatty acid synthesis. Hepatology 201052 1258-1265. (doi:10.1002/hep.23813)

38 Hozumi Y, Kawano M, Hakamata Y, Miyata M \& Jordan VC. Tamoxifen inhibits lipoprotein activity: in vivo and in vitro studies. Hormone Research 200053 36-39. (doi:10.1159/000023511)

Received 21 February 2017

Revised version received 18 April 2017

Accepted 12 May 2017 